\title{
Coulisses
}

Revue de théâtre

10 | Printemps 1994

Varia

\section{Comme un roman, Impressions}

\section{Elsa Molard}

\section{(2) OpenEdition}

\section{Journals}

Édition électronique

URL : http://journals.openedition.org/coulisses/2863

DOI : $10.4000 /$ coulisses. 2863

ISSN : 2546-9460

\section{Éditeur}

Presses universitaires de Franche-Comté

\section{Édition imprimée}

Date de publication : 1 juin 1994

Pagination : 24

ISSN : 1150-594X

\section{Référence électronique}

Elsa Molard, «Comme un roman, Impressions », Coulisses [En ligne], 10 | Printemps 1994, mis en ligne le 15 mars 2019, consulté le 23 octobre 2019. URL : http://journals.openedition.org/coulisses/2863 ; DOI : $10.4000 /$ coulisses.2863

Ce document a été généré automatiquement le 23 octobre 2019

Coulisses 


\section{Comme un roman, Impressions}

\section{Elsa Molard}

Comme un roman

\section{COMME UN ROMAN}

Conception et réafisation de $\mathcal{M}$.UZ, AR.

Création au C.D.X.N.

Le 30 novembre 1993

\section{DANIEL PENNAC}

Comme un roman

LES DROITS IMPRESCRIPTIBLES DU LECTEUR

1. Le droit de ne pas lire.

2. Le droit de sauter des pages.

3. Le droit de ne pas finir un livre.

4. Le droit de relire.

5. Le droit de lire n'importe quoi.

6. Le droit au bovarysme (maladie textuellement

transmissible).

7. Le droit de lire n'importe où.

8. Le droit de grappiller.

9. Le droit de lire à haute voix

10. Le droit de nous taire.

\section{nrf}

- On ne lit plus!

- Qui crée donc les réfractaires à la lecture?

- La télévision

1 Pennac dit «STOP » : «J'accuse », non à l'injustice! Dans son essai Comme un Roman il redonne à chacun sa part de responsabilités. Pauvre télé, bouc émissaire attitré... Les réels saboteurs de lecture potentiels sont les « 31 faut lire ", les pavés des programmes scolaires, ces bonnes intentions dictatoriales qui brandissent la littérature comme un 
bagage pour...

"On ne lit pas pour, mais contre ». Il s'agit d'un acte de résistance. Pennac ébranle les idées reçues. Il redonne à la lecture son essence première : le plaisir.

Comme un roman invite à la mise en scène. Les idées sont mises en situation: personnages, dialogues, continuité des séquences.

Six comédiens et une pianiste sous la direction de Micheline Uzan se sont appropriés ces scènes de la vie quotidienne.

Le jeu des acteurs, l'accompagnement au piano complètent les tableaux suggérés par Pennac. Le décor par exemple : la scène vide où seul trône le piano est entièrement peinte en bleu, (piano compris) et saupoudrée de nuages blancs, ce qui crée une atmosphère de rêve, de bien-être, l'univers de la lecture en somme. Au fond de la scène, une toile où le jeu des acteurs est renvoyé en ombres chinoises, "Comme au cinéma ». Comme pour rappeler que la concurrence surfaite des deux arts n'a pas lieu d'être: quand on aime la lecture quotidienne, quand on aime le rêve, ce n'est pas le cinéma, ni la télé, ni les jeux vidéo, ni rien d'autre d'ailleurs, qui pourra nous en détourner. Au contraire tout ce qui peut engendrer le rêve est l'ami de la lecture.

Ce spectacle divertissant, amusant, et antidogmatique était donc à voir, tout comme Pennac est à lire. 